\title{
The Use of AFP-Complexes to Induce Apoptosis in Cancer Cells
}

\author{
V. Pak*
}

Constab Pharmaceutical Inc., MaRS Centre, Toronto, Canada

\begin{abstract}
An anticancer "magic bullet" should have both efficacy and specificity parts. We have used an effective Apoptosis Inducer to trigger the apoptosis. A lpha-fetoprotein w as us ed to de liver A poptosis Inducers specifically to cancer cells. The AFP-AI complex inhibited tumor growth in mice, enlarged mice life survival and has shown a $50 \%$ response in patients with metastatic colorectal cancer.
\end{abstract}

Keywords: Cancer, apoptosis inducer, targeted delivery, alpha-fetoprotein, multi drug resistance.

\section{INTRODUCTION}

Cancer is the proliferation/apoptosis overbalance. Proliferation a nd apoptosis a re di fferent $\mathrm{s}$ ystems and a re us ed completely di fferently li ke the c ar ga s a nd bra ke s ystems (Fig. 1). Traditional anticancer drugs mainly aim at suppressing proliferation by any mean (more than 700 molecular targeted ag ents ar e cu rrently in tr ials), b ut d irectly a ctivating apoptosis is a better idea (less than 30 agents in trials) [1,2]. Apoptosis is responsible for recycling billions of cells everyday in the body. Cancer cells accumulate mutations in both proliferation and apoptosis systems, but crucial mutations in the apoptosis system help them to avoid the natural suicidal pathway. To ove rcome the broke $\mathrm{n}$ apoptosis elements, the drug should act "downstream" of mutated apoptosis cascade elements (Fig. 1). To trigger the apoptosis, a drug ne eds to: 1. be specific to cancer cell, 2. provide direct Apoptosis Inducer (AI) internalization, 3. Use AI acting "downstream" of the broke $\mathrm{n}$ a poptosis $\mathrm{c}$ ascade element. $\mathrm{F}$ or those purpos es, several combinations can $\mathrm{b}$ e obta ined $\mathrm{w}$ ith $\mathrm{n}$ anoparticles, immunoliposomes, cell-penetrating peptides, small molecule AIs, etc. We have prepared a non-covalent complex of alphafetoprotein (AFP) that $\mathrm{c}$ an specifically deliver AI to cancer cells and act on functional executive apoptosis elements.

\section{EFFECTIVE KILLING: DON'T REINVENT THE WHEEL - FIX THE BRAKES}

Many cancer drugs are not optimal and often ineffective since th ey ai $m$ at the targets $w$ ithin the proliferation system (for ex ample, DNA) which might not lead to the cancer cell death due to a frequent mutation of the p53 prot ein or other mutations in apoptosis pathways (Fig. 1) [3].

The probl em of s pecific a nd e ffective e limination of definite cells in the body is already solved in Nature. Cytotoxic $\mathrm{T}$ lymphocytes (CTL), for e xample, us e this mechanism. They first recognize wrong cell by membrane antigens and then use perforin for the internalization of gra nzyme B that activates caspases - the final en zymes within the ap optosis cascade (Fig. 1) [4]. Granzyme B is a direct apoptosis inducer and is not dependent on "upstream" cancer cell mutations such as p53 a nd o thers. F or this re ason, CTL $\mathrm{c}$ an

*Address correspondence to this author at the Constab Pharmaceutical Inc., MaRS Centre, Toronto, Canada; E-mail: vpak@constabpharma.com "fix the brakes" meaning they are using undamaged apoptosis el ements in side cancer ce lls (Fig. 1). Traditional ch emotherapy targeting proliferation system elements (for example, doxorubicin: DNA) c an be a ttributed to i ndirect a poptosis inducers because it can lead to the following next activation of a poptosis. Non re pairable DNA m utations caused by doxorubicin lead to p53-dependant apoptosis in normal cells. Direct a poptosis inducers on the oppos ite, trigger a poptosis themselves. The closer direct apoptosis inducer can act on a late ap optosis event less ch ances are th at cancer c ell mutations $\mathrm{m}$ ight $\mathrm{p}$ revent its a ction. The id eal $\mathrm{s}$ ituation is that caspase activators such a s the P AC- 1 m olecule, b eing the last $t$ arget in the cascade, $w$ ill activate $p$ rocaspase 3 thus triggering $\mathrm{c}$ aspase 3 a ctions a nd de monstrate an e ffective anticancer action [5].

We tried to copy the effective natural CTL "know-how" to find and kill cancer cells by combining our lessons learned from CTL and using the known biological tools.

A membrane is considered be ing the edge be tween life and death. Damage in the membrane of mitochondria, endoplasmic reticulum, lysosome or pe roxisome $\mathrm{c}$ an lead to the whole eukaryotic cell death. The membrane of mitochondria was chosen as a target because mitochondrion is a "point of no r eturn" in the in trinsic ap optosis pathway [6]. W e h ave used prove $\mathrm{n}$ a poptosis i nducers a cting on $\mathrm{m}$ itochondrion such as a tractyloside, be tulinic acid $[7,8]$ a nd an endoplasmic reticulum apoptosis inducer thapsigargin [9]. Within the intrinsic a poptosis pathway, the $\mathrm{m}$ itochondrion a cts downstream of the p53 protein. P53 is inactive in more that $50 \%$ of $\mathrm{c}$ ancer $\mathrm{c}$ ells a nd oft en 1 eads $\mathrm{t}$ o $\mathrm{m}$ ulti drug re sistance (MDR) [10]. Atractyloside was shown to induce apoptosis in p53-unfunctional HuH-7 cancer cells [11].

Since many of the agents do not cross the plasma membrane, we had to u se ag ents combined to a special delivery system in order to induce their internalization of those agents with a special delivery system. Moreover, this delivery system should have the ability to select $\mathrm{c}$ ancer cells and avoid healthy tissues.

\section{SPECIFIC DELIVERY}

AFP may be responsible for embryotoxic and teratogenic action of s ome drugs, pollutants and chemicals. One of the 


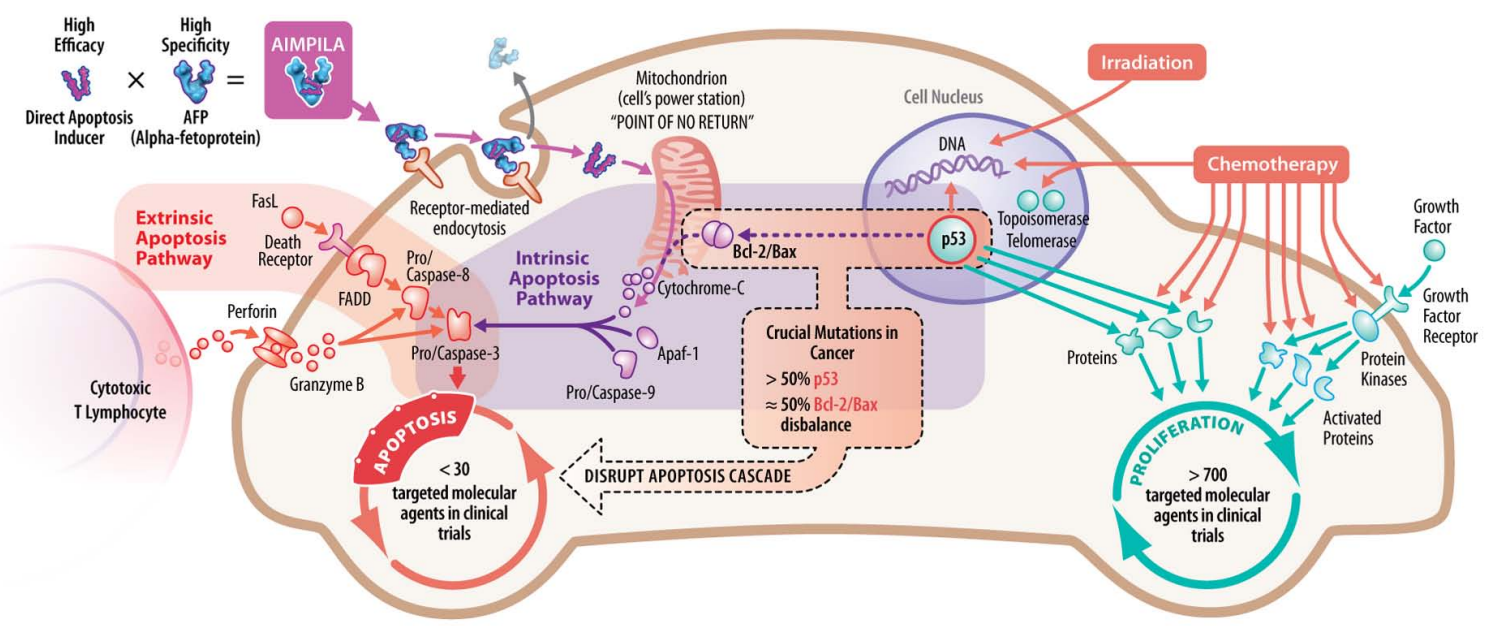

Fig. (1). Proliferation and apoptosis systems and associated anticancer drug targets. Illustration (c) 2008 AXS Biomedical Animation Studio. Used with permission.

explanations of this phenomenon is that AFP has the ability to take toxins from mother's blood and bring it to the embryo [1 2 ]. In s uch c ase, AF P s hould c ompete wit h the mother's a lbumin for bi nding to t he toxin. Am ong $m$ any other s ubstrates AF P ha $\mathrm{s}$ the s trongest bi nding a ffinity to polyunsaturated $f$ atty a cids (P UFA). Afte $r$ the AF P-PUFA complex endocytosis by e mbryo cells the PUFA is internalized [13]. W e ha ve s ubstituted the P UFA in $t$ he porc ine AFP-PUFA complex for a tractyloside and have obtained the natural effective delivery system for the powerful direct AI.

A lot of AFP conjugates were used for the targeted delivery o f d ifferent to xins to cancer cells, f or ex ample, A FPesperamicin A1 [14].

We use the non-covalent complex that is closer to natural protein form and will no $\mathrm{t}$ provoke i mmune a ttack a $\mathrm{s}$ AP conjugates can possibly do. In this case we can rely on the pharmacokinetic da ta obta ined for na tural hum an AF P i njectable drug na med "Alfetin" that wa s s hown to have 3-5 days of half-life time in the human body [15]. Pre-binding of AFP $(\mathrm{MW}=70 \mathrm{kDa})$ to atractyloside $(\mathrm{MW}=0.8 \mathrm{kDa})$ in $1: 1-2$ molar $r$ atio pos sibly do not change pure AF P pharmacokinetic profile.

\section{DISCUSSION}

AFP is a known onc ology marker $[16,17,18]$. F or the addressed delivery of the AI, we have used AFP which has highly s pecific re ceptors re -expressed on the $\mathrm{m}$ ajority of cancer cells [19] and is up taken by them [20].

AFP-mediated de livery of di oxin to c ancer c ells having AFP re ceptor (AF PR) wa s 200-1400 t imes more effective than di oxin a lone [12]. The e nvironmental t oxin di oxin is itself carcinogenic [21] and is not a direct AI, so its anticancer application is problematic.

An injectable complex of A FP $w$ ith an antifungal drug amphotericin B wa s us ed to treat $\mathrm{c}$ ancer $[22,23]$. Am photericin B does not act on mitochondrion [24] and hence is not as effective as direct AI.
We non-covalently bound AF $\mathrm{P}$ to a proven direct AI atractyloside which is toxic to the mitochondria (Fig. 1). The AFP-AI co mplex (Aimpila ${ }^{\mathrm{TM}}$ ) w as prepared as described in [25]. B riefly, the porc ine e mbryo bl ood and a mniotic fluid were collected, puri fied a nd c oncentrated wit h $50 \mathrm{kD}$ a MWCO ultrafiltration module, A FP was extracted by but anol, diafiltrated, complexed with atractyloside in 1:1-2 molar ratios and lyophilized.

The Aimpila ${ }^{\mathrm{TM}}(0.02 \mathrm{mg}$ in $0.2 \mathrm{ml}$ of oil/day) being given orally has shown to inhibit tumor growth in the $\mathrm{m}$ ice $\mathrm{p} 388$ leucosis model by $85 \%$ wi thin 25 da ys and e nlarged $m$ ice life survival by $36 \%$ [25].

The p388 1 eucosis m odel for Ai mpilatM in m ice wa $\mathrm{s}$ taken because was used before for AFP-drug conjugates testing [14].

AFP is known t o be resistant to prote olytic attack from enzymes such as trypsin [26]. The oral route for peptide and protein drug de livery for s everal drugs wa s shown be fore [27]. The p rotein of the s imilar s ize as AFP - recombinant interferon - i $\mathrm{s}$ a bsorbed from re ctal $\mathrm{s}$ uppositories and wa $\mathrm{s}$ effective to suppress replication of he patotrophic viruses in the li ver of c hildren wit h he patitis B a nd C [28]. The oil added to the drug form ulation proba bly he lped pre venting Aimpila $^{\mathrm{TM}}$ from $\mathrm{d}$ egradation in GI $\mathrm{t}$ ract a nd im proved its absorption in the intestine.

An en capsulated form of AimpilaTM ( $0.6 \mathrm{mg}$ /day) w as used a $\mathrm{s}$ m onotherapy in pa tients wit $\mathrm{h} m$ etastatic colorectal cancer ( $\mathrm{mCRC}$ ). $\mathrm{m}$ CRC $\mathrm{w}$ as ch osen b ecause co lon can cers have AFPR [19], and it was known to have $76,8 \%$ mutations of the p53 [3].

$0.012 \mathrm{mg} /$ day of the atractyloside, or $1 / \mathrm{m}$ illionth of $\mathrm{t}$ he pig's ora $1 \mathrm{LD} 50=25-100 \mathrm{mg} / \mathrm{kg}$ we re s upposed to be non toxic within Aimpila ${ }^{\mathrm{TM}}$ [26].

CT-scans b efore and after the 8 w eeks of treatment h as shown t hat 6 out of $12 \mathrm{~m}$ CRC pa tients $(50 \%)$ ha ve re sponded to a suboptimal dose of Aimpila ${ }^{\mathrm{TM}}$ [29]. Two (2) of these 6 patients have shown full reduction of metastasis, one (1) patient a $73 \%$ reduction of the size of his metastasis and 
three (3) patients were stabilized. No significant side effects, quick growth inhibition and tumor reduction were reported in that human study. This could be attributed to the way metastases $w$ ere treated by us ing a di rect a poptosis mode of Aimpila ${ }^{\mathrm{TM}}$ action.

Breast, liver, lung, ovarian, s tomach, pros tate and other cancers a re AF PR-positive [19] a nd c ould pot entially be treated with Aimpila ${ }^{\mathrm{TM}}$.

The data provided here support the idea of the necessity of the $r$ ight co mbination of $s$ pecific an $d$ ef fective $p$ arts $t o$ form an an ticancer " $m$ agic $b$ ullet". This $m$ eans a f eature which inevitably induces apoptosis in cancer cells and avoids potential $\mathrm{m}$ utation pa thways. In a ddition, a $\mathrm{s}$ econd fe ature should be added to deliver the drug only to cancer cells and internalize it for optimal results.

\section{CONCLUSION}

Aimpila $^{\mathrm{TM}}$ meets the necessary and sufficient conditions to be considered as an anticancer "m agic bullet" b ecause of its $h$ igh s pecificity to A FPR-positive $c$ ancer ce lls an $d b$ ecause it in ternalizes a tractyloside th anks to th e A FPRmediated endocytosis. Moreover, it has high efficacy in killing cancer cells due to direct apoptosis inducer action.

\section{ACNOWLEDGEMENTS}

Help a nd a dvices of $\mathrm{P}$ rof. Wa inson A. A., P ak N. A., Gagne S.Sharpe J. and Prof.Molchanov O. E are appreciated.

\section{REFERENCES}

[1] Evan G I, V ousden K H. Proliferation, cell cy cle and ap optosis in cancer. Nature 2001; 411:342-348.

[2] Oncology D rug D evelopment U pdate - M id-Year 2007, U pdated Molecularly $\mathrm{T}$ argeted A gents i n D evelopment. http://www.nmok.net/Login.aspx?ReturnUrl=\%2fnewindex.aspx (accessed February 22, 2008).

[3] Rozan LM, El-Deiry WS. p53 d ownstream target genes and tumor suppression. Cell Death and Differentiation 2007; 14: 3-9.

[4] Cytotoxic T c ell, h ttp://en.wikipedia.org/wiki/Cytotoxic_T_cell (accessed February 25, 2008).

[5] Putt KS, Chen GW, Pearson JM, et al. Small molecule activation of procaspase-3 to cas pase-3 as a per sonalized ant icancer s trategy. Nature Chem Biol 2006; 2: 543-550.

[6] Kroemer G, Zamzami N, Susin SA. Mitochodrial control of apoptosis. Immunol Today 1997; 18: 44-51.

[7] Obatomi DK, Bach PH. Biochemistry and toxicology of the diterpenoid glycoside atractyloside. Food Chem Toxicol 1998; 36: 335346.

[8] Fulda S, Sc affidi C, Su sin SA, et al. A ctivation of $m$ itochondria and release of mitochondrial apoptogenic factors by betulinic acid. J Biol Chem 1998; 18: 273(51):33942-8.

[9] Korge P, We iss J N. Th apsigargin d irectly in duces the $m$ itochondrial permeability transition. Eur J Biochem 1999; 265: 273-280.

[10] Lehnert M. Clinical multidrug resistance in cancer: a multifactorial problem. Eur J Cancer 1996; 32A: 912-920.
[11] Stewart MJ, Steenkamp V, V an der M erwe S , Z uckerman M , Crowther N J. Th e c ytotoxic e ffect of a traditional $\mathrm{Zu}$ lu r emedy, impila (Callilepis La ureola). H uman Ex p Toxicol 2 002; 2 1: 643647.

[12] Sotnichenko AI, Severin SE, Posypanova GA et al. Water-soluble 2,3,7,8-tetrachlorodibenzo-p-dioxin co mplex w ith hum an A FP: properties, toxicity in vivo, and a nti-tumor a ctivity in vivo. FEBS Lett 1999; 450: 49-51.

[13] Torres J M, G euskens M, U riel J . R eceptor-mediated en docytosis and recycling of AFP in human B-lymphoma and T-leukemia cells. Int J Cancer 1991; 47: 110-117.

[14] Severin S E, Posypanova G A, S otnichenko A I, et al. A nti-tumor activity of a covalent conjugate of the endiene antibiotic esperamicin A $1 \mathrm{w}$ ith hum an al pha-fetoprotein. D okl A cad N auk 1999; 366(4): 561-4

[15] Alfetin, h ttp://www.alfetin.ru/index-e.html ( accessed M ay 16 , 2008).

[16] Abelev GI. Alpha-fetoprotein: an insight to biology of development and to origin of tumours. Soros Educational Magazine 1998; 9: 813 .

[17] Mizejewski GJ. Alpha-fetoprotein structure and function: relevance to is oforms, e pitopes a nd c onformational $\mathrm{v}$ ariants. Ex p B iol M ed 2001; 226(5): 377-408.

[18] Mizejewski GJ. Biological roles of al pha-fetoprotein during pregnancy and perinatal development. Exp Biol Med 2004; 229: 439463.

[19] Moro R, T cherkassova J, S ong E, et al. A n ew b road-spectrum cancer marker. IVD Technology Magazine 2005; June.

[20] Laborda J, Naval J, Allouche M, Calvo M, Georgoulias V, Mishal Z, Uriel J. Specific uptake of AFP by m alignant human lymphoid cells. Int J Cancer 1987; 40: 314-318.

[21] Biswas G, Srinivasan S, Anandatheerthavarada HK, Avadhani NG. Dioxin-mediated tu mor $\mathrm{p}$ rogression th rough a ctivation of $\mathrm{m}$ itochondria-to-nucleus $\mathrm{s}$ tress $\mathrm{s}$ ignaling. $\mathrm{P} \operatorname{roc} \mathrm{N}$ atl $\mathrm{A}$ cad $\mathrm{S}$ ci $\mathrm{U}$ SA 2008; 105:1: 186-191.

[22] Pak V N, N ikonov S D, R eshetnikov S S, Pak N A, O girenko A P. Method of treatment of malignant neoplasm and complex preparation $\mathrm{h}$ aving antineoplastic a ctivity for $\mathrm{u}$ se in such tr eatment. U S Patent 6,878.688 2005; April 12.

[23] Pak V N, N ikonov S D, R eshetnikov S S, Pak N A, O girenko A P. Method of $\mathrm{c}$ ancer tr eatment a nd a m edicine for th is a pplication. Patent of Russia 2179452 2000; June 22.

[24] Rex M C, D awson D, Elliot C, El liot WH, J ones K M. Data for biochemical research. Oxford Science Publications Claredon Press Oxford Third Edition 1986; 297.

[25] Pak V. Compositions of alpha-fetoprotein and inducers of apoptosis for the treatment of cancer. PCT/CA2006/001867 2007; May 24.

http://www.wipo.int/pctdb/en/wo.jsp?wo=2007056852\&IA=WO20 07056852\&DISPLAY $=$ STATUS (accessed February 25, 2008).

[26] Mizejewski G J. N ew in sights in to A FP s tructure a nd f unction: potential biomedical applications. Alpha-fetoprotein and congenital disorders, Academic Press Inc 1985.

[27] Morishita M, Peppas NA. Is the oral route possible for peptide and protein drug delivery? Drug Discovery Today 2006; 11: 905-910.

[28] Uchaikin $\mathrm{V}, \mathrm{C}$ herednichenko $\mathrm{T}, \mathrm{M}$ alinovskaya $\mathrm{V}$, et al. $\mathrm{U}$ se of recombinant a lpha-2b-interferon in combination $w$ ith a ntioxidants in the form of rectal suppositories (viferon) in children with chronic hepatitidis B and C. Acta Virol 2000; 44: 79-83.

[29] Pak V, Molchanov O, Vincent M. Treatment of metastatic colorectal cancer w ith ai mpila, a gl ycoside/alpha-fetoprotein complex. J Clin Oncol 2007; 25: 18S: 3589. 